\title{
Conspecific individual recognition between starlings after toxicant-induced sickness
}

\author{
J. RUSSELL MASON and RUSSELL F. REIDINGER, JR. \\ Monell Chemical Senses Center, Philadelphia, Pennsylvania
}

\begin{abstract}
After feeding in the presence of a cagemate (Group $S, n=16$ ), food-deprived starlings were intubated with the toxicant methiocarb (Group $E, n=8$ ) or its nontoxic carrier, propylene glycol (Group $\mathrm{C}, \mathrm{n}=8$ ). During the 4 days after intubation, the birds in Groups $\mathrm{E}$ and $\mathrm{C}$ were presented on 2 days with the Group $S$ bird that was present during gavage (S+ bird) and on the other 2 days with another Group S bird (S- bird). Group E (but not Group C) birds were more agonistic toward S+ birds than S- birds, fed less in their presence, and were less likely to enter and perch in the same cage quadrant with them. A second experiment suggested that such differential behavior was probably not the result of behaviors exhibited by the $\mathrm{S}+$ birds. Few calls were recorded in either experiment. Although acoustic signals might have been involved, we suggest that the starlings might have used visual cues to recognize individual conspecifics that were present during aversion learning.
\end{abstract}

Birds recognize characteristics of conspecifics, such as social rank and reproductive state, and can discriminate among familiar and novel individuals (e.g., Beer, 1970; Brooks \& Falls, 1975; Emlen, 1971; Goldman, 1973; Krebs, 1971; Lein, 1981; Weiden \& Falls, 1959; Wiley \& Wiley, 1977). Vocalizations provide important cues for the recognition and discrimination of such species as the common crow (Corvus brachyrhynchos, Berger \& Ligon, 1977; Thompson, 1969), the blue jay (Cyanocitta cristata, Kramer \& Thompson, 1979), and the towhee (Pipilo erythropthalmus, Richards, 1979), which exhibit idiosyncratic patterns of calls or songs that are sufficient to permit discrimination among individuals in a flock, or among neighbors. In addition, visual, and possibly chemical, cues may contribute useful information (DeGroot, 1980).

Although not well-studied, learning (i.e., classical and/or operant conditioning) probably contributes to the development of auditory recognition among birds (Richards, 1979; Vieth, Curio, \& Ernst, 1980). Conditioning is important for individual recognition among mammals in some contexts. For example, rodents in the laboratory learn to recognize

This research was partially supported by Training Grant 5 T32 NSO7176-02 from the National Institute of Neurological and Communicative Disorders and Stroke, by BRSG Grant SO7 RR 05825-02 from the Biomedical Research Support Program, Division of Research Resources, National Institutes of Health, and by funds from the U.S. Fish and Wildlife Service. We especially thank Richard Dolbeer, Gary Beauchamp, Charles Wysocki, and Glenn Hood for criticizing earlier drafts of this manuscript. The second author is assigned to the Monell Center from the U.S. Fish and Wildlife Service, Denver Wildlife Research Center, Section of Supporting Sciences, Building 16, Federal Center, Lakewood, Colorado 80225. individual conspecifics after a single aversive experience (Pettijohn, 1981, see also: Coombes, Revusky, \& Lett, 1980; Lavin, Freise, \& Coombes, 1980). Here we report the results of two experiments designed to assess whether starlings (Sturnus vulgaris) could be trained to discriminate individual conspecifics present during a single earlier aversive feeding experience.

\section{EXPERIMENT 1}

\section{Method}

Subjects. Thirty-two male starlings (Sturnus vulgaris) were decoy trapped during March 1981 at Syracuse, New York. After arriving in the laboratory, the birds were housed in two groups $(n=16)$ in flight cages $(135 \times 90 \times 90 \mathrm{~cm})$. Such group housing decreased the potential influence of novelty among birds in the subsequent experiments. Housing and testing occurred in a room with an ambient temperature of $23^{\circ} \pm 1^{\circ} \mathrm{C}$. A $6 \mathrm{~h} / 18 \mathrm{~h}$ light-dark cycle maximized feeding without reducing the total quantity of food consumed (Rogers, 1974, 1978). Water was always available, and before the experiment began, the starlings were permitted free access to dog food (horsemeat), apples, and bird chow (Purina Flight Bird Conditioner ${ }^{1}$ ).

Procedure. After 6 weeks of adaptation to laboratory conditions, the starlings were assigned to an experimental group (Group E, $n=8$ ), a control group (Group $C, n=8$ ), or to a group of stimulus birds (Group $S, n=16$ ). Assignment was random, except that equal numbers of birds were assigned to Groups $E$, $C$, and $S$ from each of the original groups of 16. Each bird was housed individually (cage dimensions: $36 \times 41 \times 61 \mathrm{~cm}$ ), and the birds in Group $S$ were banded on the left leg with white adhesive tape (tape width: $1 \mathrm{~cm}$ ) to facilitate identification by the experimenters. Pieces of cardboard $(40 \times 41 \mathrm{~cm})$ were placed between the cages to visually isolate individuals from one another and from other birds in the laboratory. At light onset on the next day, each member of Groups $E$ and $C$ was presented with a Group $S$ bird as a cagemate. Such presentations of $S$ birds were counterbalanced with respect to the original group-housing conditions during adaptation to the laboratory, thus controlling for the possibility of differential familiarity between $S$ birds 
and the $E$ and $C$ birds. Immediately after pairing, the birds were food-deprived for $90 \mathrm{~min}$ and then given $20 \mathrm{~g}$ of $\mathrm{dog}$ food for $15 \mathrm{~min}$. While the dog food was present, the frequency and duration of four behaviors were recorded for the $E$ and $C$ birds. The behaviors were: (1) entering and perching in the same cage quadrant as the $S$ group pairmate (here defined as clumping), (2) facing the $S$ group pairmate and pecking with hackles raised (here defined as agonism), (3) feeding, and (4) calling.

After the observation period, the $\operatorname{dog}$ food was removed and the $\mathrm{E}$ birds were intubated with methiocarb $(3,5$-dimethyl-4[methylthio] phenol methylcarbamate, $0.2 \mathrm{mg} / \mathrm{kg}$ ) (Mason \& Reidinger, 1982; Rogers, 1974). C birds were intubated with methiocarb's nontoxic carrier, propylene glycol $(0.2 \mathrm{mg} / \mathrm{kg})$. $\mathrm{S}$ birds were not intubated. Intubation was completed within 15 min of the end of the feeding trial; the $E$ and $C$ birds were then returned to their cages and their $S$ group cagemates. All E birds exhibited typical symptoms of methiocarb-induced malaise (e.g., regurgitation, bill-wiping, and feather ruffling). No $\mathrm{C}$ birds exhibited such symptoms. Sixty minutes after intubation, the $S$ birds were removed from the $E$ and $C$ group cages and returned to their home cages.

On each of the 4 days following intubation, $E$ and $C$ birds were food deprived during the first $90 \mathrm{~min}$ of light and then presented with an $\mathrm{S}$ bird and $20 \mathrm{~g}$ of $\mathrm{dog}$ food for $15 \mathrm{~min}$. That $\mathrm{S}$ bird was either the individual present during intubation ( $\mathrm{S}+$ bird) or another bird (S- bird, i.e., a bird previously paired with a $\mathbf{C}$ group bird during treatment, and vice versa). Presentations of the latter $S$ bird ( $S$ - bird) served as a control for the effects of presentations, per se, of the former ( + bird). During the 15-min period, clumping, agonism, feeding, and calling by the $E$ and $C$ birds were recorded. Over the 4 test days, each of the $\mathrm{S}$ birds $(\mathrm{S}+$ and $\mathrm{S}-)$ was presented twice in a counterbalanced fasion.

\section{Results and Discussion}

Eight separate one-way analyses of variance were used to test for between-group differences before intubation in the frequency or the duration of clumping, agonism, feeding, or calling. No differences in the frequency or duration of any behavior was found ( $p s>.25$ ).

Likewise, eight separate two-way analyses of variance were used to assess differences between the $E$ and $\mathrm{C}$ birds after intubation. The independent variable in each of these analyses was groups, while the repeated variable was the frequency or duration (separate analyses) of clumping, or agonism, or feeding, or calling exhibited by $\mathrm{E}$ or $\mathrm{C}$ birds in the presence of $\mathbf{S}+$ birds versus the frequency or duration of such behaviors exhibited in the presence of $S-$ birds. Between $E$ and $C$ birds, there were significant differences in the duration of clumping $[F(1,14)=$ $4.8, p<.05]$ and feeding $[F(1,14)=4.7, p<.05]$. Also, there were significant interactions between the independent factor ( $E$ group vs. $C$ group) and the frequency and duration of clumping [Fs $(3,42)$ $=4.6,13.3$, ps $<.05$, respectively], agonism $[\mathrm{Fs}(3,42)$ $=49.2,47.1$, ps $<.05$, respectively $]$, and feeding $[\mathrm{Fs}(3,42)=5.2,6.8$, ps $<.05$, respectively]. There was no significant interaction between groups and calling $(\mathrm{p}>.25)$.

Bonferroni post hoc $t$ tests (Games, 1971) were used to identify the significant differences among means. $E$ birds showed less frequent, shorter periods
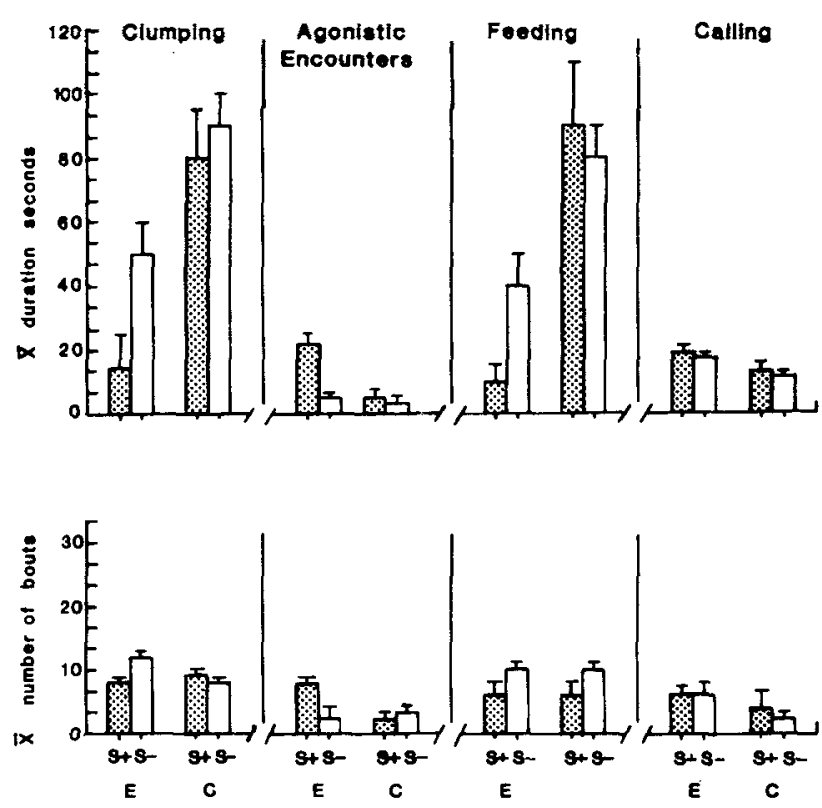

Figure 1. (Top panel) Mean duration of behaviors exhibited by experimental (E) and control (C) group birds. (Bottom panel) Mean number of bouts of behaviors exhlbited by $\mathbf{E}$ and $\mathbf{C}$ birds. Stippled bars represent behaviors exhlbited in the presence of $S+$ birds. Open bars represent behaviors exhibited in the presence of S- birds. Capped vertical bars represent standard errors of the means.

of clumping (ps $<.05$ ), more frequent, longer periods of agonism (ps $<.05$ ), and less frequent, shorter periods of feeding (ps $<.05$ ) in the presence of the $\mathrm{S}+$ bird than in the presence of the $\mathrm{S}-$ bird. $\mathrm{C}$ birds showed no such differences (Figure 1). We suggest that these differences were due to the reappearance of the $\mathrm{S}+$ birds in the cages, and we infer that the $E$ birds possessed the ability to recognize the conspecifics individually.

It seemed unlikely that the responses of the $E$ birds were influenced by behavioral differences between $\mathrm{S}+$ and $\mathrm{S}-$ birds, because each $\mathrm{S}$ bird had been paired with an $E$ and a $C$ bird during testing. However, the behaviors of the $S$ birds were not recorded, and it was still possible that after having been paired with, say, an E bird during the experimental treatment, the $S$ bird's behavior in the presence of an $\mathrm{E}$ bird might be different from that in the presence of a $\mathrm{C}$ bird. That possibility is also consistent with the notion of individual recognition, and Experiment 2 was designed to assess the importance of behaviors exhibited by the $S+$ birds.

\section{EXPERIMENT 2}

If the behaviors of the $S+$ birds were important for differential behaviors exhibited by the $E$ group, then we expected that the $S+$ birds would behave differently in the presence of the $\mathrm{E}$ birds with which 
they had been paired before intubation. Conversely, if the behaviors of the S+ birds were relatively unimportant, then we expected the $\mathrm{E}$ birds to discriminate between members of the $S$ group, even if the $\mathrm{S}+$ and $\mathrm{S}-$ birds showed similar patterns of behavior. In Experiment 2, we repeated the treatments given to the $\mathrm{E}$ birds in Experiment 1 and recorded behaviors exhibited by both $E$ and $S$ birds.

\section{Method}

Subjects. Thirty-two experimentally naive male starlings were decoy-trapped, adapted to the laboratory, and housed as in Experiment 1 .

Procedure. The birds were assigned randomly to an experimental group (Group $E, n=8$ ), a control group (Group $C, n=8$ ), or a group of stimulus birds (Group $S, n=16$ ). Intubation, testing procedures, and behavioral assessment were essentially identical to those of Experiment 1. The only differences were that the behaviors (i.e., clumping, agonism, feeding, calling) of all the groups (E, C, and S) were recorded and both $S+$ and $S-$ birds were paired with an $E$ bird or a $C$ bird before intubation. Also, clumping was more broadly defined in Experiment 2 as one bird $(E, C$, or $S)$ entering and perching in the same cage quadrant as the pairmate.

\section{Results and Discussion}

Eight one-way analyses of variance were used to test for differences in behavior among $E, C$, and $S$ birds before intubation and eight two-way analyses of variance were used to assess differences after intubation. These analyses were identical to those described in Experiment 1. Before intubation, there were no differences between groups in the frequency or duration of any of the behaviors $(p>.25)$. After intubation, however, there were differences between the groups in the duration of clumping $[F(3,28)=$ $4.2, \mathrm{p}<.05]$ and feeding $[\mathrm{F}(3,28)=3.5, \mathrm{p}<.05]$. Also, there were significant interactions between the independent factor (E vs. C vs. S groups) and the frequency and duration of clumping $[F s(9,84)=6.1,5.2$, ps $<.05$, respectively], agonism $[F s(9,84)=4.1,8.3$, ps $<.05$, respectively], and feeding $[\mathrm{Fs}(9,84)=5.9$, 9.0, ps $<.05$, respectively]. As in Experiment 1, there were no significant differences in calling.

Bonferroni post hoc $t$ tests were used to identify the significant differences among means. As in Experiment 1, the $\mathrm{E}$ birds showed fewer clumping bouts ( $p<.05)$, more frequent and longer bouts of agonism (ps $<.05$ ), and less frequent and shorter periods of feeding (ps $<.05$ ) in the presence of the $S+$ bird than in the presence of the $\mathrm{S}-$ bird. The $\mathrm{C}$ birds showed no such differences. $S$ birds paired with $E$ birds exhibited differences in clumping $(p<.05)$, but otherwise showed no differences in the frequency or duration of agonism, feeding, or calling. $S$ birds paired with $C$ birds exhibited no such differences (ps $>.25$ ) (Figure 2). We suggest, at least for the measures recorded, that behaviors exhibited by Group $S$ were unimportant for the individual recognition exhibited by Group E.
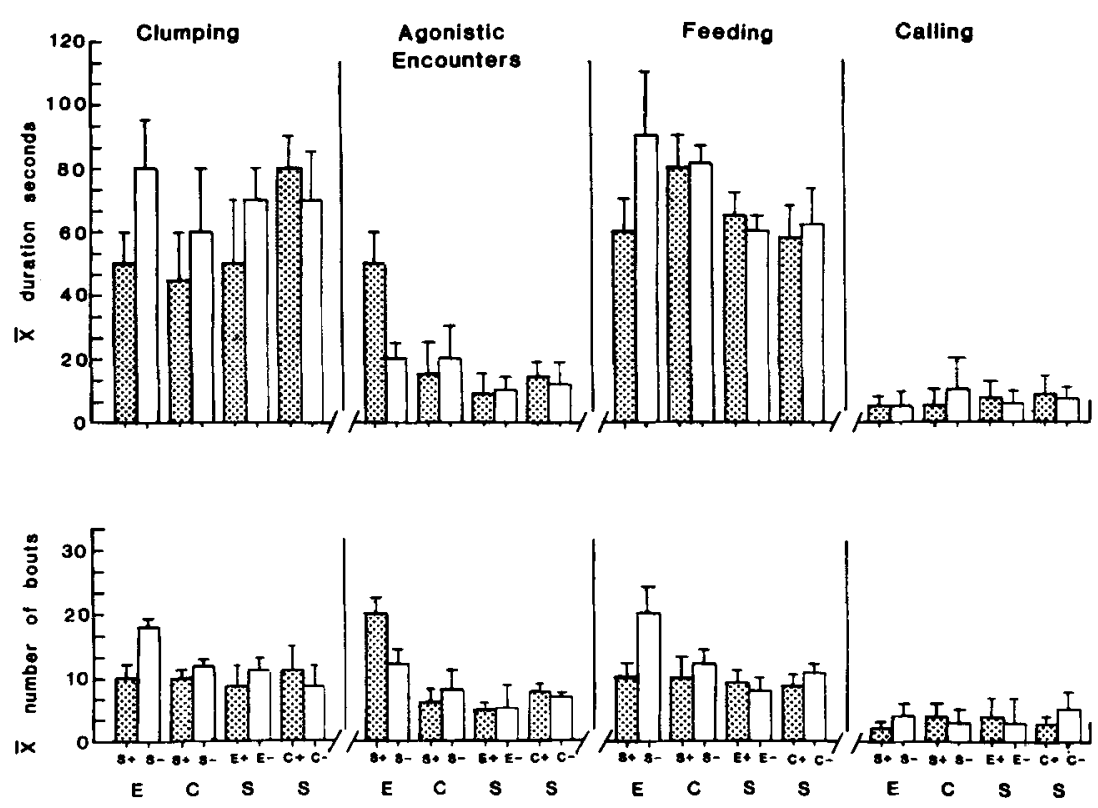

Figure 2. (Top panel) Mean duration of behgviors exhibited by experimental (E), control (C), and stimulus (S) birds towards the cagemate present during the experimental treatment (,$+ \mathbf{E}+, \mathbf{C}+$; stippled bars) or toward the other cagemate (S - , E - , C-; open bars) not present during treatment. (Bottom panel) Mean number of bouts of behaviors exhibited by $E, C$, and $S$ birds in the presence of the different cagemates. Capped vertical lines represent standard errors of the means. 


\section{GENERAL DISCUSSION}

Since few calls were exhibited by $S$ birds in Experiment 2 (Figure 2; calling by $S$ birds was not recorded in Experiment 1) and because differential behaviors were exhibited by the $E$ birds in tests during which no calls were recorded, we believe that the starlings did not use auditory cues for the individual recognition. Of course, in other contexts, vocalizations are probably important for recognition and other social interactions among starlings (e.g., Thompson, Grant, Pearson, \& Corner, 1968) and the use of subtle auditory cues in the present experiments cannot be eliminated. We have no evidence to determine what other cues the birds were using, but we believe that visual cues may have been important. In earlier experiments, visual cues appeared to be important for communication (Galasha \& Stout, 1977; Vieth et al., 1980), food preference (e.g., Mason \& Reidinger, 1981; Turner, 1965), and aversion learning (e.g., Brower, 1969; Mason \& Reidinger, 1982; Nashman, Rauschenberger, \& Ashe, 1977; Schuler, 1980).

Our findings are consistent with other work demonstrating that animals learn about factors other than food or drink present in an aversive feeding or drinking context (Archer, Sjödén, Nilsson, \& Carter, 1980). Whether conditioned social aversions occur in natural settings as they do in the laboratory is unclear. Although cautious about extrapolating from the laboratory to the field, we speculate that, for birds, conditioned social aversions could have broad consequences. Many avian species show a marked cohesion of activity while feeding, and the evidence suggests that such cohesion is based on visual information. Crook (1961), for example, has reported that quelea (Quelea quelea) observe one another during feeding and that such observations effectively synchronize behavior. Conceivably, conditioned social aversions could produce an opposite effect, precipitating dissynchronous behavior and group dispersion. That possibility seems plausible insofar as both ducks (Cairina moschataj, Anas platyrhyncus, Klopfer, 1957, 1959) and red-wings (Agelaius phoeniceus, Mason \& Reidinger, 1982) readily display aversions to visual stimuli on the basis of observational learning.

It remains unclear whether conditioned social aversions would generalize to nonfeeding contexts, but there is reason to expect that such generalization might occur. Unlike other forms of aversion learning, food aversions, and presumably exteroceptive cues (e.g., conspecifics) associated with ingestion of food, transfer relatively well (Garcia, Kovner, \& Green, 1970; Johnston, Zahorik, Immler, \& Zakon, 1978). We speculate that starlings, which merely observe the interaction of a pair of con- specifics (i.e., an $E$ and an $S+$ bird), could form a learned aversion for the $S+$ bird.

\section{REFERENCES}

Archer, T., Sjödén, P.-O., Nilsson, L. G., \& Carter, N. Exteroceptive context in taste-aversion conditioning and extinction: Odour, cage, and bottle stimuli. Quarterly Journal of Experimental Psychology, 1980, 32, 197-214.

BEE R, C. G. Individual recognition of voice in the social behavior of birds. In D. S. Lehrman, R. A. Hinde, \& E. Shaw (Eds.), Advances in animal behavior. New York: Academic Press, 1970.

Berger, L. R., \& Ligon, J. D. Vocal communication and individual recognition in the piñon jay (Gymnorhinus cyanocephalus). Animal Behaviour, 1977, 25, 567-584.

BrooKs, R. J., \& Falls, J. B. Individual recognition by song in white-throated sparrows. I. Discrimination of songs by neighbors and strangers. Canadian Journal of Zoology, 1975, 53, 879-888.

Brower, L. P. Ecological chemistry. Scientific American, 1969, 220, 22-29.

Coomees, S., Revusky, S., \& LETT, B. T. Long-delay taste aversion learning in an unpoisoned rat: Exposure to a poisoned rat as the unconditioned stimulus. Learning and Motivation, 1980 , 11, 256-266.

Crook, J. H. The basis of flock organisation in birds. In W. H. Thorpe \& O. L. Zangwill (Eds.), Current problems in animal behaviour. Cambridge: Cambridge University Press, 1961.

DEGRoot, $P$. Information transfer in a socially-roosting weaver bird (Quelea quelea; Ploceinae): An experimental study. Animal Behaviour, 1980, 28, 1249-1254.

EmLEN, S. T. The role of song in individual recognition in the indigo bunting. Zeitschrift für Tierpsychologie, 1971, 28, 241-246.

Galasha, J. G., \& Stout, J. F. Aggressive communication by Larus glaucescens. Part IV: Experiments on visual communication. Behaviour, 1977, 62, 222-235.

Games, P. A. Multiple comparison of means. American Educational Research Journal, 1971, 8, 531-565.

Garcia, J., Kovner, R., \& Green, K. F. Cue properties versus palatability of flavors in avoidance learning. Psychonomic Science, 1970, 20, 313-314.

Goldman, P. Song recognition by field sparrows. Auk, 1973, 90, 106-113.

Johnston, R. E., Zahorik, D. M., Immler, K., \& Zakon, H. Alterations of male sexual behavior by learned aversions to hamster vaginal secretion. Journal of Comparative and Physiological Psychology, 1978, 92, 85-93.

KLOPFER, P. H. Empathetic learning in ducks. American Naturalist, 1957, 91, 61-63.

KLOPFER, P. H. Social interactions in discrimination learning with special reference to feeding behaviour in birds. Behaviour, 1959, 14, 282-299.

Kramer, H. G., \& Thompson, N. S. Geographic variation in the bell calls of the blue jay (Cyanocitta cristata). Auk, 1979, 96, 423-425.

KREBs, J. B. Territory and breeding density in the great tit, Parus major L. Ecology, 1971, 52, 2-22.

Lavin, M. J., Freise, B., \& Coombes, S. Transferred flavor aversions in adult rats. Behavioral and Neural Biology, 1980, 28, 15-33.

LEIN, M. R. Display behavior of ovenbirds (Seiurus aurocappilus). II. Song variation and singing behavior. Wilson Bulletin, 1981, $93,21-41$.

Mason, J. R., \& Reidinger, R. F. Effects of social facilitation and observational learning on feeding behavior of the redwinged blackbird. (Agelaius phoeniceus). Auk, 1981, 98, 778-784. 
Mason, J. R., \& Reidinger, R. F. Observational learning of food aversions in red-winged blackbirds (Agelaius phoeniceus). Auk, 1982, 99, 548-554.

Nachman, M. J., Rauschenberger, J., \& Ashe, J. H. Stimulus characteristics in food aversion learning. In N. W. Milgram, L. Krames, \& T. M. Alloway (Eds.), Food aversion learning. New York: Plenum Press, 1977.

Pettijohn, T. F. Conditioned social aversion in the male mongolian gerbil (Meriones unguiculatus). Journal of Comparative and Physiological Psychology, 1981, 95, 228-239.

Richands, D. G. Recognition of neighbors by associative learning in rufous-sided towhees. $A u k, 1979,96,688-693$.

Roanns, J. G. Responses of caged red-winged blackbirds to two types of repellents. Journal of Wildlife Management, 1974, 38, 418-423.

ROGERs, J. G. Some characteristics of conditioned taste aversions in red-winged blackbirds. Auk, 1978, 95, 362-369.

Schuler, W. Factors influencing learning to avoid unpalatable prey in birds re-learning new alternative prey and similarity of appearance of alternative prey. Zietschrift für Tierpsychologie, $1980,54,105-143$.

Thompson, N. S. Individual identification and temporal patterning in the cawing of common crows. Communications in Behavioral Biology, No. 09690044, 1969.
Thompson, R. D., Grant, C. Z., Pearson, E. W., \& Corner, G. W. Differential heart rate response of starlings to sound stimuli of biological origin. Journal of Wildlife Management, 1968, 32, 888-893.

Turner, E. R. A. Social feeding in birds. Behaviour, 1965, 24, $1-46$.

Vieth, W., Curio, E., \& Ernst, U. The adaptive significance of avian mobbing. III. Cultural transmission of enemy recognition in blackbirds. Cross-species tutoring and properties of learning. Animal Behaviour, 1980, 28, 1217-1229.

WEIDEN, J. S., \& FALLS, J. B. Differential responses of male ovenbirds to recorded songs of neighboring and more distant individuals. Auk, 1959, 76, 343-351.

WILEY, R. H., \& WILEY, M. S. Recognition of neighbors' duets by stripe-backed wrens (Campylorhynchus nuchalis). Behaviour, 1977, 62, 10-34.

\section{NOTE}

1. Reference to trade names does not imply endorsement, by the U.S. Government, of commercial products.

(Manuscript received February 19, 1982; revision accepted for publication April 25, 1983.) 